\title{
The Effects of Distance and Duration of Exposure to Electromagnetic Radiation of Hair Dryer on Rat Sperm Parameters
}

\author{
Shirin Safari ${ }^{1,2}$, Seyed Mohammad Javad Mortazavi ${ }^{3}$, Niloofar Aghazade3, Yousof Mousavi ${ }^{1,2}$ \\ ${ }^{1}$ Department of Anatomy-Physiology, Khatam Al-Nabieen University, Kabul, Afghanistan \\ ${ }^{2}$ Researches and Technology Center, Khatam Al-Nabieen University, Kabul, Afghanistan \\ ${ }^{3}$ Ionizing and Non-Ionizing Radiation Protection Research Center (INIRPRC), Shiraz University of Medical Sciences, Shiraz, Iran \\ Email: *Safari.knurtc@knu.edu.af
}

How to cite this paper: Safari, S., Mortazavi, S.M.J., Aghazade, N. and Mousavi, Y. (2020) The Effects of Distance and Duration of Exposure to Electromagnetic Radiation of Hair Dryer on Rat Sperm Parameters. Journal of Biosciences and Medicines, 8, 17-27.

https://doi.org/10.4236/jbm.2020.86002

Received: April 14, 2020

Accepted: May 23, 2020

Published: May 26, 2020

Copyright $\odot 2020$ by author(s) and Scientific Research Publishing Inc. This work is licensed under the Creative Commons Attribution International License (CC BY 4.0).

http://creativecommons.org/licenses/by/4.0/

(c) (i) Open Access

\begin{abstract}
Background: As a part of modern life, using electromagnetic field exposure has increased. EMFs might produce a variety of adverse effects on different parts of human body including the reproductive system. The consequences of exposure to the emitted EMFs from a hair dryer on sperm parameters were the major concerns of the present study. Materials and Methods: Fifty four adult Male Sprague-Dawley rats were randomly assigned to 9 groups. Samples from all experimental groups received exposure with two different modes: switch on (hot wind) and switch off (cold wind). Samples of group 1 (control) maintained under experimental conditions without any exposure. The exposure protocol for samples in groups 2 to 9 were $10 \mathrm{~cm}$ at $10 \mathrm{~min}-\mathrm{on}, 10$ $\mathrm{cm}$ at $10 \mathrm{~min}$-off, $10 \mathrm{~cm}$ at $20 \mathrm{~min}-\mathrm{on}, 10 \mathrm{~cm}$ at $20 \mathrm{~min}-\mathrm{off}, 20 \mathrm{~cm}$ at 10 min-on, $20 \mathrm{~cm}$ at $10 \mathrm{~min}-$ off, $20 \mathrm{~cm}$ at $20 \mathrm{~min}-\mathrm{on}, 20 \mathrm{~cm}$ at $20 \mathrm{~min}-$ off. After exposure sperm motility was analyzed with a light microscope as a blind experiment. Nonparametric tests were used to detect statistically significant differences between different groups. Results: Findings of our study indicated no significant changes in the frequency of sluggish and non-motile sperms of rats in the control group compared to all treatment groups and showed statistically significant differences between the relative frequency of progressive sperms in control group rats compared to all treatment groups except groups 2 and 7. There were no statically significant changes between groups with different time and distance. Sperm count and morphology were not affected by microwave emitted from hair dryer. Conclusion: Exposure to the hair dryer microwaves affects sperm motility, which is amongst the key parameters determining the chance of conceiving.
\end{abstract}




\section{Keywords}

Electromagnetic Field, Microwaves, Hair Dryer, Sperm Motility

\section{Introduction}

Infertility and its related challenges are considered unavoidable problems in a couple's life. The most common reason of male infertility is inability to produce sufficient normal active sperm [1]. Male infertility during the past several decades is as a result of direct or indirect exposure to certain environmental factors such as radio-frequency electromagnetic waves (RF-EMW) [2] [3] [4] [5]. There are electromagnetic field exposures everywhere, at home or workplaces as a result of different types of common electrical equipment such as refrigerators, washing machines and kettles [6] [7]. Even the building wiring as an invisible environmental pollutant factor is harmful to animals and human health [8]. Ambient electromagnetic fields produced by various electrical devices and from power transmission lines expose human beings undoubtedly [9]. As a part of modern life, using electromagnetic fields especially the extremely low frequency electromagnetic fields [ELFEMF] has increased. Both high energy sources like power lines and microwaves and low energy devices like cell phones can produce such fields [10].

We can categorize electromagnetic sources into two groups: natural electromagnetic sources (atmospheric discharges like thunder, sun, some distant stars or human body) and unnatural or human made sources (printers, vacuum cleaners, cell phones, hair dryers, microwaves) [11] [12], electrical home equipment, computers, cables that carry electrical currents, Television [13], radio and TV base stations, mobile phone base stations and phone equipment [14] [15]. A lot of investigations have carried out to evaluate the effects of electromagnetic fields on human health, histologically and also physiologically [7] [8] [9] [16] [17] [18] [19]. A common health issue is the safety of human exposure to various electromagnetic field sources [20]. Electromagnetic field may cause a variety of adverse in vivo effects such as headaches, chronic fatigue, cataracts, chest pain, heart disease, stress, forgetfulness, nausea, effects on learning and memory, reproductive system [13] [21], CNS, endocrine, immune system [22] [23], sleep disorders, alterations of biological functions in human and animals and also modifications of electroencephalographic activity [24] [25]. EMFs also can cause an increase of the risk of life-threatening illnesses such as leukemia [26] [27] [28], brain cancer [28] [29], breast and lung tumors [22] [23] [30], Lou Gehrig's disease [31], increased risk of miscarriage, childhood morbidity, de novo mutations, genotoxicity and neurodegenerative disease, infertility and birth defects [32] [33] [34], amyotrophic lateral sclerosis, depression [35] [36], birth defects [37], committing suicide [38], and Alzheimer's' disease [39]. Male fertility potential has been decreased by using electronic household equipment and cell phones 
by inducing pathological changes in sperm parameters and testes, morphology, decreasing sperm count, motility and viability [40]. DNA breaks, protein misfolding and cell growth inhibition are the result of increasing free radicals and $\left[\mathrm{Ca}^{2+}\right]$ as an effect of EMFs. The effect of EMFs exposure on reproductive system depends on frequency and wave strength and duration of exposure [20]. Spermatogenesis, Sertoli and Leydig cells can be badly affected by EMFs [9] [41] [42]. Some studies show the atrophy of the seminiferous tubules of experimental animals caused by EMFs [17]. Few studies are available on how cell phone waves affect sperm parameters. Wdowiak, et al. [43] showed that cell phone waves in people who used it, reduced the motility and percentage of sperm with normal morphology. Besides, these waves decreased motility, viability, and count of sperms with normal morphology [4] [44].

Human being in developed society will be exposed to EMFs at home and at work, inevitably, but should be aware of the harmful effects of EMFs. To have healthy reproductive system people should try to avoid EMF exposure and use techniques to relieve EMF radiation [20]. The hair dryer is a common used instrument at home and barber shops. The consequences of exposure to the emitted EMFs from a hair dryer on sperm parameters were the major concerns of the present study.

\section{Materials and Methods}

\subsection{Animals}

Fifty four adult male Sprague-Dawley rats weighing between 200 and $250 \mathrm{~g}$ (11 12 weeks old), obtained from an inbred colony were housed in groups of four per cage and free access to food and water. Animals were kept under stable room temperature $\left(23^{\circ} \mathrm{C} \pm 2^{\circ} \mathrm{C}\right)$ and a $12 \mathrm{~h} \mathrm{light/dark}$ cycle (the light period started at 7 A.M.). All Experimental procedure was conducted in accordance with the ethical guidelines set by the ethical committee of Khatam al-Nabieen University and Shiraz University of Medical Sciences. All experiments were arranged to be done from 10 to 12 A.M. to avoid any circadian rhythm induced bias. Rats were carefully handled to minimize unwanted stress during the housing and experiments.

\subsection{Experimental Design}

The rats were randomly assigned to 9 groups of 6 rats in each group. Samples collected from each group treated according to Table 1. Distances and durations are according to the way people, specially barbers, normally use hair dryer.

For the collection of samples, the rats were anesthetized with diethyl ether, the animals were cervical dislocated and the peritoneal cavity was opened through a lower transverse abdominal incision. Thereafter, the epididymis was immediately removed in all experimental and control groups. The cauda epididymis was cut into pieces and placed in a petri dish containing $2 \mathrm{ml}$ medium of Ham's F-10 and incubated at $37^{\circ} \mathrm{C}$ (with $5 \% \mathrm{CO}_{2}$ ) for 15 minutes.

Group 1 comprised the control group and samples received from this group 
Table 1. Experimental design.

\begin{tabular}{ccccc}
\hline Group & N & Distance $(\mathrm{cm})$ & Time $(\mathrm{min})$ & Switch \\
\hline 1 (control) & 6 & - & 20 & - \\
2 & 6 & 10 & 10 & on \\
3 & 6 & 10 & 10 & off \\
4 & 6 & 10 & 20 & on \\
5 & 6 & 10 & 20 & off \\
6 & 6 & 20 & 10 & on \\
7 & 6 & 20 & 10 & off \\
8 & 6 & 20 & 20 & on \\
9 & 6 & 20 & 20 & off \\
\hline
\end{tabular}

maintained under experimental conditions without any exposure, the other experimental groups have different duration of exposure with different distance to the source of exposure (hair dryer). Samples from all experimental groups received exposure with two different modes: switch on (hot wind) and switch off (cold wind).

The exposure protocol for samples in groups 2 to 9 were $10 \mathrm{~cm}$ at $10 \mathrm{~min}-\mathrm{on}$, $10 \mathrm{~cm}$ at $10 \mathrm{~min}$-off, $10 \mathrm{~cm}$ at $20 \mathrm{~min}-\mathrm{on}, 10 \mathrm{~cm}$ at $20 \mathrm{~min}$-off, $20 \mathrm{~cm}$ at 10 min—on, $20 \mathrm{~cm}$ at $10 \mathrm{~min}-\mathrm{off}, 20 \mathrm{~cm}$ at $20 \mathrm{~min}-\mathrm{on}, 20 \mathrm{~cm}$ at $20 \mathrm{~min}-$ off. Samples were placed in a Gumi box in order not to be affected by the temperature and a thermometer was placed in the box to control the temperature. After exposure sperm motility was analyzed with a light microscope as a blind experiment.

For evaluation of sperm motility, one drop of sperm suspension was placed on a microscopic slide and their motility was determined as progressive (rapid and slow), in situ or sluggish and non-motile levels using $40 \times$ objective lens.

\subsection{Hair Dryer}

A hair dryer (Johnson super $1800 \mathrm{~W}$-Italy) was used in this study as an RF exposure source.

\subsection{Data Analysis}

Non-parametric Kruskal-Wallis and Mann-Whitney tests were used to detect significant differences between different groups. All statistical analysis was performed by using SPSS version 21. Differences amongst means were considered statistically significant if the $\mathrm{P}<0.05$. The results are expressed as mean \pm SEM.

\section{Results}

Table 2 shows short term exposure of samples to microwave emitted from the hair dryer, indicating no significant changes in the frequency of sluggish and non-motile sperms of rats in the control group compared to all treatment groups 
Table 2. Comparison of the sperm motility in different groups.

\begin{tabular}{cccc}
\hline Groups & Non-motile & Sluggish & Progressive \\
\hline 1 & $87.55 \pm 2.61$ & $11.2 \pm 2.24$ & $1.21 \pm 0.51^{*}$ \\
2 & $90.41 \pm 2.96$ & $9.08 \pm 2.75$ & $0.48 \pm 0.32$ \\
3 & $94.35 \pm 1.27$ & $5.42 \pm 1.21$ & $0.18 \pm 0.12^{\star}$ \\
4 & $88.58 \pm 2.16$ & $11.06 \pm 2.09$ & $0.12 \pm 0.09^{*}$ \\
5 & $92.99 \pm 1.32$ & $6.42 \pm 1.25$ & $0.53 \pm 0.50^{*}$ \\
6 & $84.46 \pm 2.52$ & $15.19 \pm 2.46$ & $0.29 \pm 0.17^{*}$ \\
7 & $89.29 \pm 2.04$ & $10.11 \pm 1.97$ & $0.37 \pm 0.24$ \\
8 & $91.34 \pm 1.14$ & $10.28 \pm 1.98$ & $0.11 \pm 0.08^{\star}$ \\
9 & $87.93 \pm 2.31$ & $11.40 \pm 2.16$ & $0.18 \pm 0.10^{*}$ \\
\hline
\end{tabular}

These data show the difference in sperm motility in different groups. All values were expressed as mean \pm SEM. Groups with the same asterisks are significantly different. ${ }^{*} \mathrm{P}<0.05, \mathrm{n}=6$ per group.

and showed statistically significant differences between the relative frequency of progressive sperms in control group rats compared to that of group 3; exposed for $10 \mathrm{~min}$ at $10 \mathrm{~cm}$ distance, switch off $(\mathrm{P}=0.016)$, group $4 ; 20 \mathrm{~min}$ at $10 \mathrm{~cm}$, switch on $(\mathrm{P}=0.015)$ and group $5 ; 20 \mathrm{~min}$ at $10 \mathrm{~cm}$, switch off $(\mathrm{P}=0.015)$ and group 6; $10 \mathrm{~min}$ at $20 \mathrm{~cm}$, switch on $(\mathrm{P}=0.045)$ and group $8 ; 20 \mathrm{~min}$ at $20 \mathrm{~cm}$, switch on $(\mathrm{P}=0.015)$ and group $9 ; 20 \mathrm{~min}$ at $10 \mathrm{~cm}$, switch off $(\mathrm{P}=0.038)$ (Figure 1). Sperm morphology was not affected by microwave emitted from hair dryer (Table 3 ). There were no statically significant differences in sperm count between different groups (Table 4). No statically significant changes were seen between groups with different time and distance.

The number of progressive sperms are significantly different in all experimental groups (except group 2 and 7) compared with normal control. The number of sluggish and non-motile sperms didn't show any significant differences in all groups. Data are expressed as mean \pm SEM. ${ }^{*} \mathrm{P}<0.05, \mathrm{n}=6$ per group.

\section{Discussion}

To our knowledge, the current study provides the first available detailed information on the effects of distance and duration of exposure to electromagnetic radiation of hair dryer on rat sperm parameters.

Infertility caused by male factors, as one of the parameters in this study, is a major concern during the past several decades. Several investigations showed that direct or indirect exposure to RF-EMW as the main environmental factor plays a dominant role in decreasing the male fertility [45].

The results of the present study indicate that exposure to microwave radiation emitted from a hair dryer influences sperm motility that is the main factor of sperm parameters.

The findings of this study are generally in line with the results obtained in studies on mobile jammers [46] as well as other different sources of electromagnetic fields such as mobile phones, as mentioned earlier [4] [40] [45] [47], laptops 


\section{sperm motility in different groups}

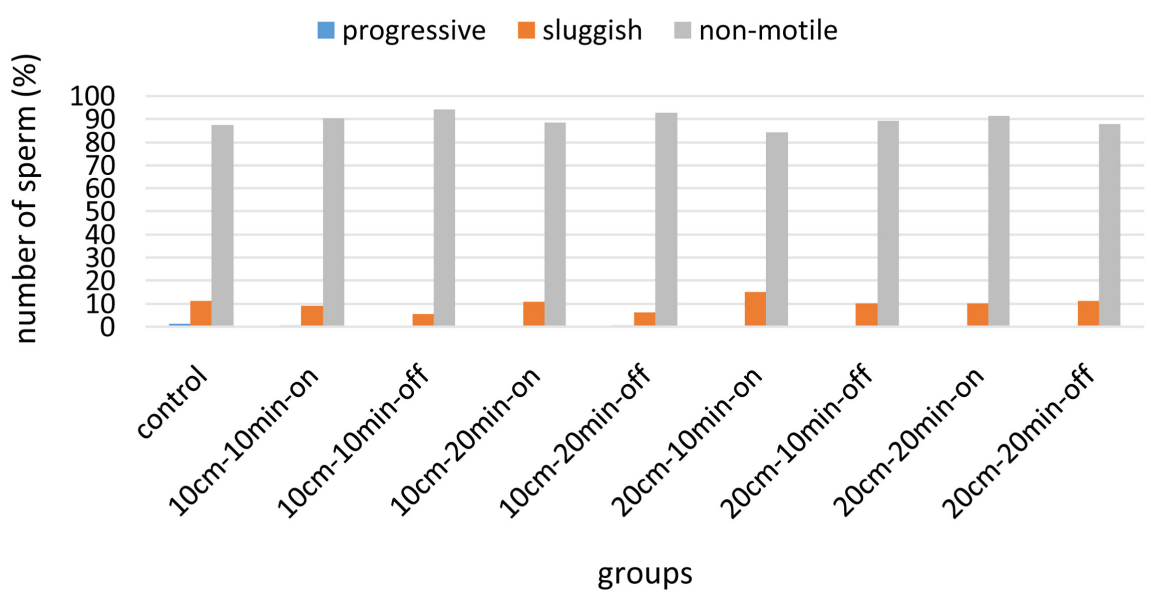

Figure 1. The effects of exposure to electromagnetic radiation of hairdryer on rat sperm motility.

Table 3. Comparison of the percentage of normal and abnormal sperm morphology in different groups.

\begin{tabular}{ccc}
\hline Groups & Normal morphology & Abnormal morphology \\
\hline 1 & $99.2 \pm 1.19$ & $0.83 \pm 1.19$ \\
2 & $99.1 \pm 0.83$ & $0.91 \pm 0.83$ \\
3 & $97.7 \pm 1.27$ & $2.27 \pm 1.27$ \\
4 & $98.0 \pm 0.74$ & $2.00 \pm 0.74$ \\
5 & $98.9 \pm 1.04$ & $1.09 \pm 1.04$ \\
6 & $98.5 \pm 1.21$ & $1.55 \pm 1.21$ \\
7 & $97.9 \pm 2.17$ & $2.09 \pm 2.17$ \\
8 & $99.3 \pm 1.19$ & $0.73 \pm 1.19$ \\
9 & $97.9 \pm 2.17$ & $2.09 \pm 2.17$ \\
\hline
\end{tabular}

Values are expressed as mean \pm standard errors of the mean (SEM). No statically significant differences were seen in sperm morphology between different groups. $\mathrm{P} \leq 0.05, \mathrm{n}=6$ per group.

Table 4. Comparison of the percentage of sperm count in different groups.

\begin{tabular}{cc}
\hline Groups & Sperm count $\left(\times 10^{6} / \mathrm{ml}\right)$ \\
\hline 1 & $25.90 \pm 6.22$ \\
2 & $26.72 \pm 4.71$ \\
3 & $32.21 \pm 8.37$ \\
4 & $27.85 \pm 9.45$ \\
5 & $22.45 \pm 6.03$ \\
6 & $24.45 \pm 9.35$ \\
7 & $27.01 \pm 1.00$ \\
8 & $27.01 \pm 1.01$ \\
9 & $27.85 \pm 9.45$
\end{tabular}

Values are expressed as mean \pm standard errors of the mean (SEM). No statically significant differences were seen in sperm count between different groups. $\mathrm{P} \leq 0.05, \mathrm{n}=6$ per group. 
or wireless internet-connected laptops [33] [48]. Several studies suggest that rats exposed to 900 or $1800 \mathrm{MHz}$ GSM RF radiation (1 h/day for 28 days) showed a statistically significant lower proportion of motile sperms [49] or there is a statistically significant decrease in sperm motility in rabbits exposed to 800 or 900 $\mathrm{MHz}$ GSM RF radiation (8 h/day for 12 weeks) in standby mode [50] [51]. Another study also revealed significant decreased motility and viability and increased reactive oxygen species (ROS) in fresh semen samples from 23 healthy donors and 7 infertile patients after 1 hour exposure to cell phone radiation in “talk" mode [4].

Also, Khaki et al. exposed rats to electromagnetic field for 40 days and reported a significant increase in apoptosis in testis, percentage of testis vein congestion, and a significant decrease in testis weight, serum testosterone. Despite our findings, the effects were different according to the frequency, duration of exposure, and strength of EMFs [52].

Erogul et al. also reported a significant decrease in percentage of fast and slow progressive sperms and increased percentages of immotile and non-progressive sperms after they exposed fresh human semen to $900 \mathrm{~Hz}$ radiofrequency electromagnetic radiation and evaluated the motility of sperms [40].

In vitro human epidemiologic studies on men exposed to radiofrequency radiation revealed a significant decline in sperm count, motility and increased reactive oxidative stress, as reviewed by La Vignera et al. [53]. However, the results of the current study are not compatible with those reported by Falzone et al. who exposed the density-purified human sperm to $900 \mathrm{MHz}$ cell phone radiation and didn't see any significant difference between exposed and control samples regarding sperm kinematic parameters [54].

Oxidative stress produced in the testicular organ as a result of EMF exposure leads to a build-up of free radicals and ROS levels in sperm. Sperms are susceptible to destruction from oxidative stress because of the high concentration of polyunsaturated fatty acids in their membranes and few stores of antioxidant enzymes [1].

\section{Conclusion}

It can also be concluded from the findings of this study that, exposure to microwave radiation emitted from a hair dryer affects sperm parameters such as motility which are among the key parameters determining the chance of conceiving. Thus, because of the extensive use of hair dryers, further researches in different times and distances are required. It is also suggested that individuals who spend more time using a hair dryer like barbers be monitored periodically in terms of reproductive system health.

\section{Conflicts of Interest}

The authors declare no conflicts of interest regarding the publication of this paper. 


\section{References}

[1] Agarwal, A., Singh, A., Hamada, A. and Kesari, K. (2011) Cell Phones and Male Infertility: A Review of Recent Innovations in Technology and Consequences. International Brazilian Journal of Urology, 37, 432-454. https://doi.org/10.1590/S1677-55382011000400002

[2] Boivin, J., Bunting, L., Collins, J.A. and Nygren, K.G. (2009) Reply: International Estimates on Infertility Prevalence and Treatment Seeking: Potential Need and Demand for Medical Care. Human Reproduction, 24, 2380-2383. https://doi.org/10.1093/humrep/dep218

[3] Skakkebæk, N.E., et al. (2006) Is Human Fecundity Declining? International Journal of Andrology, 29, 2-11. https://doi.org/10.1111/j.1365-2605.2005.00573.x

[4] Agarwal, A., et al. (2009) Effects of Radiofrequency Electromagnetic Waves (RF-EMW) from Cellular Phones on Human Ejaculated Semen: An in Vitro Pilot Study. Fertility and Sterility, 92, 1318-1325. https://doi.org/10.1016/j.fertnstert.2008.08.022

[5] De Iuliis, G.N., Newey, R.J., King, B.V. and Aitken, R.J. (2009) Mobile Phone Radiation Induces Reactive Oxygen Species Production and DNA Damage in Human Spermatozoa in Vitro. PLOS ONE, 4, e6446.

https://doi.org/10.1371/journal.pone.0006446

[6] Fernie, K.J. and Reynolds, S.J. (2005) The Effects of Electromagnetic Fields from Power Lines on Avian Reproductive Biology and Physiology: A Review. Journal of Toxicology and Environmental Health, Part B, 8, 127-140. https://doi.org/10.1080/10937400590909022

[7] Hashem, M. and El-Sharkawy, N. (2009) Hemato-Biochemical and Immunotoxicological Effects of Low Electromagnetic Field and Its Interaction with Lead Acetate in Mice. Iraqi Journal of Veterinary Sciences, 23, 105-114.

[8] Abo-Neima, S.E., Motaweh, H.A. and Ragab, M.F. (2015) Effects of Electric Field on Histopathological Study, Electrical Properties and Enzymes Function of Liver of Albino Rats. Journal of Advanced Physics, 4, 120-128. https://doi.org/10.1166/jap.2015.1179

[9] Khayyat, L.I. (2011) The Histopathological Effects of an Electromagnetic Field on the Kidney and Testis of Mice. EurAsian Journal of BioSciences, 5, 103-109. https://doi.org/10.5053/ejobios.2011.5.0.12

[10] Van Deventer, T., Saunders, R. and Repacholi, M. (2005) WHO Health Risk Assessment Process for Static Fields. Progress in Biophysics and Molecular Biology, 87, 355-363. https://doi.org/10.1016/j.pbiomolbio.2004.08.017

[11] Bracken, M.B., et al. (1995) Exposure to Electromagnetic Fields during Pregnancy with Emphasis on Electrically Heated Beds: Association with Birthweight and Intrauterine Growth Retardation. Epidemiology, 6, 263-270. https://doi.org/10.1097/00001648-199505000-00013

[12] Khaki, A.A., Alihemmati, A. and Nobahari, R. (2015) A Study of the Effects of Electromagnetic Field on Islets of Langerhans and Insulin Release in Rats.

[13] Szemerszky, R., Zelena, D., Barna, I. and Bárdos, G. (2010) Stress-Related Endocrinological and Psychopathological Effects of Short- and Long-Term $50 \mathrm{~Hz}$ Electromagnetic Field Exposure in Rats. Brain Research Bulletin, 81, 92-99. https://doi.org/10.1016/j.brainresbull.2009.10.015

[14] Ongel, K., Gumral, N. and Ozguner, F. (2009) The Potential Effects of Electromagnetic Field: A Review. Cell Membranes and Free Radical Research, 1, 85-89.

[15] Gholampour, F., Owji, S. and Javadifar, T. (2011) Chronic Exposure to Extremely 
Low Frequency Electromagnetic Field Induces Mild Renal Damages in Rats. International Journal of Zoological Research, 7, 393-400. https://doi.org/10.3923/ijzr.2011.393.400

[16] Al-Glaib, B., Al-Dardfi, M., Al-Tuhami, A., Elgenaidi, A. and Dkhil, M. (2008) A Technical Report on the Effect of Electromagnetic Radiation from a Mobile Phone on Mice Organs. The Libyan Journal of Medicine, 3, 8. https://doi.org/10.3402/ljm.v3i1.4743

[17] Zare, S., Alivandi, S. and Ebadi, A. (2007) Histological Studies of the Low Frequency Electromagnetic Fields Effect on Liver, Testes and Kidney in Guinea Pig. World Applied Sciences Journal, 2, 509-511.

[18] Khaki, A.A., Zarrintan, S., Khaki, A. and Zahedi, A. (2008) The Effects of Electromagnetic Field on the Microstructure of Seminal Vesicles in Rat: A Light and Transmission Electron Microscope Study. Pakistan Journal of Biological Sciences. PJBS, 11, 692-701. https://doi.org/10.3923/pjbs.2008.692.701

[19] Lotfi, S. (2011) Effect of Electromagnetic Radiation Emitted from a Mobile Phone Station on Biochemical and Histological Structure of Some Rat Organs. Isotope and Radiation Research, 43, 95-103.

[20] Gye, M.C. and Park, C.J. (2012) Effect of Electromagnetic Field Exposure on the Reproductive System. Clinical and Experimental Reproductive Medicine, 39, 1-9. https://doi.org/10.5653/cerm.2012.39.1.1

[21] Picazo, M., et al. (1995) Long-Term Effects of ELF Magnetic Fields on the Mouse Testis and Serum Testosterone Levels. Electro- and Magnetobiology, 14, 127-134. https://doi.org/10.3109/15368379509022552

[22] Mohamed, D.A. and Elnegris, H.M. (2015) Histological Study of Thyroid Gland after Experimental Exposure to Low Frequency Electromagnetic Fields in Adult Male Albino Rat and Possible Protective Role of Vitamin E. Journal of Cytology \& Histology, 6, 1. https://doi.org/10.4172/2157-7099.1000374

[23] Ahlbom, A. (2001) Neurodegenerative Diseases, Suicide and Depressive Symptoms in Relation to EMF. Bioelectromagnetics, 22, S132-S143. https://doi.org/10.1002/1521-186X(2001)22:5+<::AID-BEM1029>3.0.CO;2-V

[24] Ebrahim, S., Azab, A.E., Albasha, M.O. and Albishti, N. (2016) The Biological Effects of Electromagnetic Fields on Human and Experimental Animals. International Journal of Natural and Applied Sciences, 3, 106-121.

[25] Marzook, E.A., El Moneim, A.E.A. and Elhadary, A.A. (2014) Protective Role of Sesame Oil against Mobile Base Station-Induced Oxidative Stress. Journal of Radiation Research and Applied Sciences, 7, 1-6. https://doi.org/10.1016/j.jrras.2013.10.010

[26] Bastuji-Garin, S., Richardson, S. and Zittoun, R. (1990) Acute Leukaemia in Workers Exposed to Electromagnetic Fields. European Journal of Cancer and Clinical Oncology, 26, 1119-1120. https://doi.org/10.1016/0277-5379(90)90266-V

[27] London, S.J., Thomas, D.C., Bowman, J.D., Sobel, E., Cheng, T.C. and Peters, J.M. (1991) Exposure to Residential Electric and Magnetic Fields and Risk of Childhood Leukemia. American Journal of Epidemiology, 134, 923-937. https://doi.org/10.1093/oxfordjournals.aje.a116176

[28] Savitz, D.A. and Loomis, D.P. (1995) Magnetic Field Exposure in Relation to Leukemia and Brain Cancer Mortality among Electric Utility Workers. American Journal of Epidemiology, 141, 123-134.

https://doi.org/10.1093/oxfordjournals.aje.a117400

[29] Harrington, J., McBride, D., Sorahan, T., Paddle, G. and Van Tongeren, M. (1997) 
Occupational Exposure to Magnetic Fields in Relation to Mortality from Brain Cancer among Electricity Generation and Transmission Workers. Occupational and Environmental Medicine, 54, 7-13. https://doi.org/10.1136/oem.54.1.7

[30] Loomis, D.P., Savitz, D.A. and Ananth, C.V. (1994) Breast Cancer Mortality among Female Electrical Workers in the United States. JNCI: Journal of the National Cancer Institute, 86, 921-925. https://doi.org/10.1093/jnci/86.12.921

[31] Johansen, C. and Olsen, J.H. (1998) Mortality from Amyotrophic Lateral Sclerosis, Other Chronic Disorders, and Electric Shocks among Utility Workers. American Journal of Epidemiology, 148, 362-368. https://doi.org/10.1093/oxfordjournals.aje.a009654

[32] Gharagozloo, P. and Aitken, R.J. (2011) The Role of Sperm Oxidative Stress in Male Infertility and the Significance of Oral Antioxidant Therapy. Human Reproduction, 26, 1628-1640. https://doi.org/10.1093/humrep/der132

[33] Mahmoudi, R., et al. (2015) Effects of Microwave Electromagnetic Radiations Emitted from Common Wi-Fi Routers on Rats' Sperm Count and Motility. International Journal of Radiation Research, 13, 363-368.

[34] Behari, J. and Rajamani, P. (2012) Electromagnetic Field Exposure Effects (ELF-EMF and RFR) on Fertility and Reproduction. BioInitiative Working Group.

[35] Verkasalo, P.K., Kaprio, J., Varjonen, J., Romanov, K., Heikkilä, K. and Koskenvuo, M. (1997) Magnetic Fields of Transmission Lines and Depression. American Journal of Epidemiology, 146, 1037-1045.

https://doi.org/10.1093/oxfordjournals.aje.a009232

[36] Iyer, M.B., Schleper, N. and Wassermann, E.M. (2003) Priming Stimulation Enhances the Depressant Effect of Low-Frequency Repetitive Transcranial Magnetic Stimulation. Journal of Neuroscience, 23, 10867-10872. https://doi.org/10.1523/JNEUROSCI.23-34-10867.2003

[37] Blaasaas, K., Tynes, T., Irgens, Å. and Lie, R. (2002) Risk of Birth Defects by Parental Occupational Exposure to $50 \mathrm{~Hz}$ Electromagnetic Fields: A Population Based Study. Occupational and Environmental Medicine, 59, 92-97. https://doi.org/10.1136/oem.59.2.92

[38] Reichmanis, M., Perry, F.S., Marino, A.A. and Becker, R.O. (1979) Relation between Suicide and the Electromagnetic Field of Overhead Power Lines. Physiological Chemistry and Physics, 11, 395-403.

[39] Sobel, E., Dunn, M., Davanipour, Z., Qian, Z. and Chui, H. (1996) Elevated Risk of Alzheimer's Disease among Workers with Likely Electromagnetic Field Exposure. Neurology, 47, 1477-1481. https://doi.org/10.1212/WNL.47.6.1477

[40] Erogul, O., et al. (2006) Effects of Electromagnetic Radiation from a Cellular Phone on Human Sperm Motility: An in Vitro Study. Archives of Medical Research, 37, 840-843. https://doi.org/10.1016/j.arcmed.2006.05.003

[41] Forgács, Z., et al. (2004) Effects of Whole-Body 50-Hz Magnetic Field Exposure on Mouse Leydig Cells. The Scientific World Journal, 4, 83-90. https://doi.org/10.1100/tsw.2004.182

[42] Aydin, M., Turk, G., Yuksel, M., Cevik, A., Apaydin, A. and Yilmaz, S. (2007) Effect of Electromagnetic Field on the Sperm Characteristics and Histopathological Status of Testis in Rats. Medycyna Weterynaryjna, 63, 178-183.

[43] Wdowiak, A., Wdowiak, L. and Wiktor, H. (2007) Evaluation of the Effect of Using Mobile Phones on Male Fertility. Annals of Agricultural and Environmental Medicine, 14, 169-172. 
[44] Yan, J.-G., Agresti, M., Bruce, T., Yan, Y.H., Granlund, A. and Matloub, H.S. (2007) Effects of Cellular Phone Emissions on Sperm Motility in Rats. Fertility and Sterility, 88, 957-964. https://doi.org/10.1016/j.fertnstert.2006.12.022

[45] Agarwal, A., Deepinder, F., Sharma, R.K., Ranga, G. and Li, J. (2008) Effect of Cell Phone Usage on Semen Analysis in Men Attending Infertility Clinic: An Observational Study. Fertility and Sterility, 89, 124-128. https://doi.org/10.1016/j.fertnstert.2007.01.166

[46] Mortazavi, S., Parsanezhad, M., Kazempour, M., Ghahramani, P., Mortazavi, A. and Davari, M. (2013) Male Reproductive Health under Threat: Short Term Exposure to Radiofrequency Radiations Emitted by Common Mobile Jammers. Journal of Human Reproductive Sciences, 6, 124. https://doi.org/10.4103/0974-1208.117178

[47] Ghanbari, M., Mortazavi, S.B., Khavanin, A. and Khazaei, M. (2013) The Effects of Cell Phone Waves (900 MHz-GSM Band) on Sperm Parameters and Total Antioxidant Capacity in Rats. International Journal of Fertility \& Sterility, 7, 21. https://doi.org/10.5812/jhs.8230

[48] Avendano, C., Mata, A., Sarmiento, C.A.S. and Doncel, G.F. (2012) Use of Laptop Computers Connected to Internet through Wi-Fi Decreases Human Sperm Motility and Increases Sperm DNA Fragmentation. Fertility and Sterility, 97, 39-45.e2. https://doi.org/10.1016/j.fertnstert.2011.10.012

[49] Mailankot, M., Kunnath, A.P., Jayalekshmi, H., Koduru, B. and Valsalan, R. (2009) Radio Frequency Electromagnetic Radiation (RF-EMR) from GSM (0.9/1.8 GHz) Mobile Phones Induces Oxidative Stress and Reduces Sperm Motility in Rats. Clinics, 64, 561-565. https://doi.org/10.1590/S1807-59322009000600011

[50] Salama, N., Kishimoto, T., Kanayama, H.-O. and Kagawa, S. (2009) Retracted: The Mobile Phone Decreases Fructose But Not Citrate in Rabbit Semen: A Longitudinal Study. Systems Biology in Reproductive Medicine, 55, 181-187. https://doi.org/10.3109/19396360903013126

[51] Salama, N., Kishimoto, T. and Kanayama, H.O. (2010) Retracted: Effects of Exposure to a Mobile Phone on Testicular Function and Structure in Adult Rabbit. International Journal of Andrology, 33, 88-94. https://doi.org/10.1111/j.1365-2605.2008.00940.x

[52] Khaki, A., Imani, S. and Golzar, F.S. (2012) Effects of Rosmarinic Acid on Male Sex Hormones (Testosterone-FSH-LH) and Testis Tissue Apoptosis after Exposure to Electromagnetic Field (EMF) in Rats. African Journal of Pharmacy and Pharmacology, 6, 248-252. https://doi.org/10.5897/AJPP11.701

[53] La Vignera, S., Condorelli, R.A., Vicari, E., D’Agata, R. and Calogero, A.E. (2012) Effects of the Exposure to Mobile Phones on Male Reproduction: A Review of the Literature. Journal of Andrology, 33, 350-356.

https://doi.org/10.2164/jandrol.111.014373

[54] Falzone, N., Huyser, C., Fourie, F., Toivo, T., Leszczynski, D. and Franken, D. (2008) In Vitro Effect of Pulsed $900 \mathrm{MHz}$ GSM Radiation on Mitochondrial Membrane Potential and Motility of Human Spermatozoa. Bioelectromagnetics, 29, 268-276. https://doi.org/10.1002/bem.20390 